\title{
Pulmonary hypertension due to acute respiratory distress syndrome
}

\author{
S.A. Namendys-Silva ${ }^{1,2}$, L.E. Santos-Martínez ${ }^{3}$, T. Pulido ${ }^{3}$, E. Rivero-Sigarroa ${ }^{1}$, \\ J.A. Baltazar-Torres ${ }^{1}$, G. Domínguez-Cherit ${ }^{1}$ and J. Sandoval ${ }^{3}$
}

${ }^{1}$ Departamento de Terapia Intensiva, Instituto Nacional de Ciencias Médicas y Nutrición Salvador Zubirán, Mexico City, Mexico

${ }^{2}$ Departamento de Terapia Intensiva, Instituto Nacional de Cancerología, Mexico City, Mexico

${ }^{3}$ Departamento de Cardioneumología, Instituto Nacional de Cardiología Ignacio Chávez, Mexico City, Mexico

\begin{abstract}
Our aims were to describe the prevalence of pulmonary hypertension in patients with acute respiratory distress syndrome (ARDS), to characterize their hemodynamic cardiopulmonary profiles, and to correlate these parameters with outcome. All consecutive patients over 16 years of age who were in the intensive care unit with a diagnosis of ARDS and an in situ pulmonary artery catheter for hemodynamic monitoring were studied. Pulmonary hypertension was diagnosed when the mean pulmonary artery pressure was $>25 \mathrm{mmHg}$ at rest with a pulmonary artery occlusion pressure or left atrial pressure $<15 \mathrm{mmHg}$. During the study period, 30 of 402 critically ill patients (7.46\%) who were admitted to the ICU fulfilled the criteria for ARDS. Of the 30 patients with ARDS, 14 met the criteria for pulmonary hypertension, a prevalence of $46.6 \%$ (95\% Cl; $28-66 \%)$. The most common cause of ARDS was pneumonia (56.3\%). The overall mortality was $36.6 \%$ and was similar in patients with and without pulmonary hypertension. Differences in patients' hemodynamic profiles were influenced by the presence of pulmonary hypertension. The levels of positive end-expiratory pressure and peak pressure were higher in patients with pulmonary hypertension, and the $\mathrm{PaCO}_{2}$ was higher in those who died. The level of airway pressure seemed to influence the onset of pulmonary hypertension. Survival was determined by the severity of organ failure at admission to the intensive care unit.
\end{abstract}

Key words: Pulmonary hypertension; Acute respiratory distress syndrome; Pulmonary artery catheter; Intensive care unit

\section{Introduction}

Pulmonary hypertension $(\mathrm{PH})$ includes a group of diseases characterized by a progressive increase in pulmonary vascular resistance (PVR) leading to right ventricular failure (RVF) and death (1). $\mathrm{PH}$ is diagnosed when the mean pulmonary artery pressure (mPAP) is $>25 \mathrm{mmHg}$ at rest in the presence of a pulmonary artery occlusion pressure (PAOP) or left atrial pressure $<15 \mathrm{mmHg}$ (2-4). Acute respiratory distress syndrome (ARDS) is a clinical entity characterized by damage to the alveolar epithelium and the endothelial barrier of the pulmonary vessels, inflammation, and noncardiogenic pulmonary edema that lead to acute respiratory failure (5). The Berlin definition classifies ARDS as mild [ratio of partial pressure of arterial $\mathrm{O}_{2}$ to the fraction of inspired $\mathrm{O}_{2}\left(\mathrm{PaO}_{2} /\right.$ $\left.\mathrm{FIO}_{2}\right) \leq 300 \mathrm{mmHg}$, and $>200 \mathrm{mmHg}$ with positive endexpiratory pressure (PEEP) or continuous positive airway pressure (CPAP) $\geq 5 \mathrm{~cm} \mathrm{H} \mathrm{H}_{2} \mathrm{O}$, moderate $\left(\mathrm{PaO}_{2} / \mathrm{FIO}_{2}\right.$ $\leq 200 \mathrm{mmHg}$, and $>100 \mathrm{mmHg}$ with PEEP $\geq 5 \mathrm{~cm} \mathrm{H} \mathrm{H}_{2} \mathrm{O}$ ), or severe $\left(\mathrm{PaO}_{2} / \mathrm{FIO}_{2} \leq 100 \mathrm{mmHg}\right.$ with $\mathrm{PEEP} \geq 5 \mathrm{~cm}$ $\mathrm{H}_{2} \mathrm{O}$ ) (6). Approximately $10-15 \%$ of patients admitted to an intensive care unit (ICU), and more than $20 \%$ of patients undergoing invasive mechanical ventilation have been shown to meet the ARDS criteria (7). The mortality reported in different studies is $25-30 \%(8,9)$. In patients with ARDS, it is common to observe persistent systolic artery pulmonary pressure (sPAP) $>30 \mathrm{mmHg}$ or mPAP $>25 \mathrm{mmHg}$ (10). Critically ill patients may develop $\mathrm{PH}$ as a result of ARDS, sepsis, heart failure or left acute pulmonary thromboembolism (11).

Few studies have described the cardiopulmonary hemodynamic profile of critically ill patients in the ICU. The true prevalence of $\mathrm{PH}$ in patients with ARDS is not

Correspondence: S.A. Namendys-Silva, Department of Critical Care Medicine, Instituto Nacional de Ciencias Médicas y Nutrición Salvador Zubirán, Vasco de Quiroga Número 15, Colonia Sección XVI, Delegación Tlalpan, C.P. 14000, Mexico City, Mexico. Fax: +52-555655510. E-mail: snamendys@incan.edu.mx

Presented in part at Chest 2013, the 79th Annual Meeting of the American College of Chest Physicians, October 26-31, Chicago, IL, USA

Received July 1, 2013. Accepted June 2, 2014. First published online August 8, 2014. 
well established. Beiderlinden et al. (12) reported a prevalence of $\mathrm{PH}$ of $92 \%$ in a heterogeneous group of ARDS patients. Differences in reported prevalence may result from differences in the cohorts studied with respect to the etiology of ARDS (primary vs secondary), hemodynamic characteristics, and concomitant therapeutic interventions (e.g., permissive hypercapnia, the level of PEEP, and the use of inotropes or vasopressors). This situation is complicated by difficulties in defining $\mathrm{PH}$ properly and understanding its pathophysiology and magnitude in patients with ARDS. As a result, the impact of $\mathrm{PH}$ as an independent variable in the evolution of ARDS and the survival of patients with ARDS has been difficult to define. However, there is indirect evidence (13) that the right ventricular dysfunction caused by $\mathrm{PH}$ adversely affects outcome. Knowledge of the prevalence and prognostic significance of $\mathrm{PH}$ could suggest therapeutic interventions for more effective management of $\mathrm{PH}$ in critically ill patients with ARDS and improve their prognosis.

The purpose of this study was to describe the prevalence of $\mathrm{PH}$ in patients with ARDS, to characterize their hemodynamic and cardiopulmonary profiles and to correlate those parameters with outcome.

\section{Material and Methods}

This observational and descriptive cohort study was approved by the Institutional Review Board and performed at the Instituto Nacional de Ciencias Médicas y Nutrición Salvador Zubirán, Mexico City, from March 2007 to February 2008. The hospital has 130 beds, and the medical-surgical ICU has 14 beds, with medical and nursing staff who are qualified in intensive care. At least one intensivist and eight nurses are on duty 24 hours a day (8-hour shifts). All the nurses receive regular training in intensive care, and the ICU has a nurse-to-patient ratio of 1:2. Routine clinical rounds, including medical (fellows and attending physicians) and nursing staff and meetings with internists, pulmonologists, rheumatologists, oncologists, endocrinologists, hematologists, nutritionists, surgeons and infectious disease specialists are carried out daily in the ICU. Approximately 450 patients are admitted to the ICU each year. All consecutive patients older than 16 years of age who were in the ICU with a diagnosis of ARDS, and an in situ pulmonary artery catheter (PAC) for hemodynamic monitoring were eligible. Demographic variables, hemodynamics, need for inotropic agents or vasopressors, reason for admission to the ICU, cause of ARDS, length of stay in the ICU, duration of monitoring with a PAC, and death in the ICU were recorded. The Acute Physiology and Chronic Health Evaluation (APACHE) II score was calculated at $24 \mathrm{~h}(14)$ and the Sequential Organ Failure Assessment (SOFA) score (15) was calculated on admission to the ICU. Pressure recording was performed and hemodynamic parameters calculated using the PAC. The PAOP was obtained prior to the completion of an expiratory pause. A chest radiograph was taken in the anteroposterior projection with portable equipment to verify the position of the distal end of the PAC within the proximal pulmonary artery. In our ICU, PAC is used for determining the etiology of shock, lactic acidosis, pulmonary edema (cardiogenic vs noncardiogenic), oliguric renal failure, pulmonary hypertension, and cardiac abnormalities such as mitral regurgitation, atrial and ventricular septal defects, and cardiac tamponade. It is also used to guide titration of fluid therapy and vasoactive infusions (16). All patients were mechanically ventilated using the ARDSNet protocol (17). Respiratory system compliance was calculated as the tidal volume divided by the difference between the inspiratory plateau pressure and PEEP (18). All consecutive patients with ARDS who were admitted to the ICU during the study period were included.

We used the Berlin definition of ARDS (6). PH was diagnosed when the mPAP was $>25 \mathrm{mmHg}$ at rest with a PAOP or left atrial pressure $<15 \mathrm{mmHg}(2-4)$, and RVF was defined as an mPAP $>25 \mathrm{mmHg}$, right atrial pressure greater than PAOP, and stroke volume index $<30 \mathrm{~L} \cdot \mathrm{min}^{-1} \cdot \mathrm{m}^{2}$ (19). We calculated the diastolic pulmonary arterial pressure-pulmonary PAOP gradient (dPAP-PAOP).

\section{Statistical analysis}

Statistical analyses were performed using the Statistical Package for the Social Sciences software (version 20.1, SPSS, USA). Continuous variables are reported as means $\pm S D$, or as a percentage for categorical variables. The Student $t$-test was used to compare continuous variables because all of them were normally distributed (determined using the Kolmogorov-Smirnov test). The chisquare or the Fisher exact test was used to compare categorical variables. The association of variables was examined using the Pearson or Spearman correlation, depending on the sampling distribution. In all cases, a $\mathrm{P}$ value $<0.05$ was considered to be statistically significant.

\section{Results}

During the study period, 402 critically ill patients were admitted to the ICU, 30 patients $(7.46 \%)$ fulfilled the criteria for ARDS, and of those, 14 met the criteria for $\mathrm{PH}$, resulting in a prevalence of $46.6 \%(95 \% \mathrm{Cl}=28-66 \%)$. All patients received invasive mechanical ventilation. The general characteristics of the study patients are presented in Table 1. The mean age of the patients was 50 years; 14 were female. The most common cause of ARDS was pneumonia $(56.3 \%)$, and ARDS was of primary origin in $70 \%$ of cases. Twenty-three patients $(76.7 \%)$ met the criteria for moderate ARDS (Table 1). The overall mortality was $36.6 \%(11 / 30)$; five of the patients who died met the diagnostic criteria for $\mathrm{PH}$. Table 2 presents the hemodynamic profiles and Table 3 the arterial blood gas analyses and ventilator profiles of both groups of patients. The levels of PEEP and peak pressure (PP) were significantly higher 
Table 1. Demographic and clinical data of ARDS patients.

\begin{tabular}{|c|c|c|c|c|}
\hline & All patients $(n=30)$ & Without PH $(n=16)$ & $\mathrm{PH}(\mathrm{n}=14)$ & $\mathrm{P}$ \\
\hline Female & 14 [46.6 (28.3-65.6)] & 8 [50 (24.6-75.3)] & $6[42(17.6-71.1)]$ & $0.696^{b}$ \\
\hline Age (years) & $49.43 \pm 16.31$ & $48.75 \pm 17.44$ & $50.21 \pm 15.54$ & $0.811^{\mathrm{a}}$ \\
\hline \multicolumn{5}{|l|}{ Berlin definition ARDS } \\
\hline Moderate & 23 [76.7 (57.7-90.0)] & 14 [87.5 (61.6-98.4)] & 9 [64.3 (35.1-87.2)] & $0.204^{b}$ \\
\hline Severe & 7 [23.3 (9.9-42.2)] & 2 [12.5 (1.5-38.3)] & 5 [35.7 (12.7-64.8)] & \\
\hline \multicolumn{5}{|l|}{ Causes of ARDS } \\
\hline Pneumonia & 17 [56.3 (37.4-74.5)] & 9 [56.3 (29.8-80.2)] & 8 [57.1 (28.8-82.3)] & $0.586^{b}$ \\
\hline Abdominal sepsis & $6[20(7.7-38.5)]$ & $4[25(7.2-52.3)]$ & $2[14.3(1.7-42.8)]$ & \\
\hline Acute pancreatitis & 4 [13.3 (3.7-30.7)] & $1[6.3[0.1-30.2)]$ & 2 [21.4 (1.7-42.8)] & \\
\hline Bronchoaspiration & $3[10(2.1-26.5)]$ & 2 [12.5 (1.5-38.3)] & 1 [7.1 (1.8-33.8)] & \\
\hline \multicolumn{5}{|l|}{ Type of ARDS } \\
\hline Primary & 21 [70 (50.6-85.2)] & 12 [75 (47.6-92.7)] & 9 [64.3 (35.1-87.2)] & $0.694^{b}$ \\
\hline Secondary & 9 [30 (14.7-49.3)] & $4[25(7.2-52.3)]$ & 5 [35.7 (12.7-64.8)] & \\
\hline \multicolumn{5}{|l|}{ Vasoactive drugs } \\
\hline Norepinephrine & 23 [76.6 (57.7-90.0)] & 12 [75 (47.6-92.7)] & 11 [78.6 (49.2-95.3)] & $0.818^{b}$ \\
\hline Dobutamine & 14 [46.6 (28.3-65.5)] & $4[25(7.2-52.3)]$ & 10 [71.4 (41.9-91.6)] & $<0.001^{\mathrm{b}}$ \\
\hline Milrinone & $2[6.6(0.8-22.0)]$ & 0 & $2[14.3(1.7-42.8)]$ & $0.209^{b}$ \\
\hline SOFA score & $9.53 \pm 2.98$ & $9.56 \pm 3.18$ & $9.50 \pm 2.84$ & $0.309^{a}$ \\
\hline APACHE II score & $16.97 \pm 4.76$ & $16.13 \pm 5.50$ & $17.93 \pm 3.73$ & $0.955^{a}$ \\
\hline Mortality & 11 [36.6 (19.9-56.1)] & 6 [37.5 (15.2-64.5)] & 5 [35.7 (12.7-64.8)] & $0.919^{b}$ \\
\hline
\end{tabular}

Data are reported as $\mathrm{n}[\%(95 \% \mathrm{Cl})]$ except for age, SOFA and APACHE II scores. ARDS: acute respiratory distress syndrome; PH: pulmonary hypertension; SOFA: sequential organ failure assessment; APACHE: acute physiologic and chronic health evaluation. The ${ }^{a}$ Student $t$-test, and ${ }^{\mathrm{b}}$ chi-square or the Fisher exact test were used for statistical analyses.

in the $\mathrm{PH}$ group (Table 3). Table 4 shows the hemodynamic profiles of all of the study patients and their outcomes. $\mathrm{PaCO}_{2}$ was significantly higher in the patients who died (Table 5). There were no differences in the hemodynamic profiles, arterial blood gas parameters or the ventilator parameters of the patients with and without $\mathrm{PH}$ or of those who lived or died. Only one patient (3.33\%) met the criteria for RVF. There was a small but significant correlation $(r=0.427, P=0.019)$ between the dPAP-PAOP gradient and the level of PEEP used in mechanical ventilation.

Table 2. Hemodynamic profile of ARDS patients.

\begin{tabular}{lccrr}
\hline & All patients $(\mathrm{n}=30)$ & $\mathrm{PH}(\mathrm{n}=14)$ & Without PH $(\mathrm{n}=16)$ & $\mathrm{P}$ \\
\hline HR $(\mathrm{bpm})$ & $92.70 \pm 16.33$ & $91.57 \pm 18.18$ & $93.68 \pm 20.83$ & 0.771 \\
RAP $(\mathrm{mmHg})$ & $9.47 \pm 2.60$ & $10.43 \pm 2.56$ & $8.63 \pm 2.41$ & 0.059 \\
SPAP $(\mathrm{mmHg})$ & $37.60 \pm 13.75$ & $48.07 \pm 12.82$ & $28.44 \pm 5.54$ & $<0.001$ \\
dPAP $(\mathrm{mmHg})$ & $22.20 \pm 8.72$ & $28.79 \pm 7.10$ & $16.44 \pm 5.25$ & $<0.001$ \\
mPAP $(\mathrm{mmHg})$ & $27.07 \pm 10.29$ & $36.07 \pm 7.50$ & $19.19 \pm 3.78$ & $<0.001$ \\
dPAP-POAP $(\mathrm{mmHg})$ & $11.37 \pm 8.69$ & $16.64 \pm 8.93$ & $6.75 \pm 5.32$ & $<0.001$ \\
POAP $(\mathrm{mmHg})$ & $10.83 \pm 2.98$ & $12.14 \pm 2.59$ & $9.69 \pm 2.89$ & $<0.001$ \\
CI $\left(\mathrm{L} \cdot \mathrm{min}-1 \cdot \mathrm{m}^{-2}\right)$ & $3.41 \pm 0.87$ & $3.40 \pm 1.08$ & $3.41 \pm 0.67$ & 0.958 \\
RVSWI $\left(\mathrm{g} \cdot \mathrm{min}^{-1} \cdot \mathrm{m}^{-2}\right)$ & $9.19 \pm 5.03$ & $11.15 \pm 5.78$ & $7.49 \pm 3.64$ & $<0.001$ \\
LVSWI $\left(\mathrm{g} \cdot \mathrm{min}^{-1} \cdot \mathrm{m}^{-2}\right)$ & $39.50 \pm 12.24$ & $37.82 \pm 14.24$ & $40.96 \pm 10.46$ & 0.495 \\
SVRI $\left(\right.$ dynas $\left.\cdot \mathrm{s}^{-1} \cdot \mathrm{cm}^{-5} \cdot \mathrm{cm}^{-2}\right)$ & $1817.17 \pm 666.09$ & $1781.00 \pm 648.78$ & $1848.81 \pm 700.50$ & 0.786 \\
PVRI $\left(\right.$ dynas $\left.\cdot \mathrm{s}^{-1} \cdot \mathrm{cm}^{-5} \cdot \mathrm{cm}^{-2}\right)$ & $371.27 \pm 249.128$ & $514.50 \pm 289.03$ & $245.94 \pm 108.10$ & $<0.001$ \\
\hline
\end{tabular}

Data are reported as means $\pm S D$. ARDS: acute respiratory distress syndrome; PH: pulmonary hypertension; HR: heart rate; RAP: right atrial pressure; SPAP: systolic pulmonary artery pressure; dPAP: diastolic pulmonary artery pressure; mPAP: mean pulmonary artery pressure; PAOP: pulmonary artery occlusion pressure; Cl: cardiac index; RVSWI = right ventricular stroke work index; LVSWI: left ventricular stroke work index; SVRI: systemic vascular resistance index; PVRI: pulmonary vascular resistance index. The Student $t$-test was used for statistical analyses. 
Table 3. Blood gas and ventilatory parameters of ARDS patients.

\begin{tabular}{|c|c|c|c|c|}
\hline & All patients $(n=30)$ & $\mathrm{PH}(n=14)$ & Without $\mathrm{PH}(n=16)$ & $P$ \\
\hline Tidal volume $(\mathrm{mL})$ & $536.80 \pm 42.69$ & $545.57 \pm 42.55$ & $529.13 \pm 42.67$ & 0.301 \\
\hline PEEP $\left(\mathrm{cmH}_{2} \mathrm{O}\right)$ & $12.27 \pm 3.62$ & $13.71 \pm 3.40$ & $11.0 \pm 3.42$ & $<0.001$ \\
\hline $\mathrm{RSC}\left(\mathrm{mL} / \mathrm{cmH}_{2} \mathrm{O}\right)$ & $31.01 \pm 6.88$ & $28.4 \pm 5.30$ & $33.20 \pm 7.40$ & 0.054 \\
\hline $\mathrm{PP}\left(\mathrm{cmH}_{2} \mathrm{O}\right)$ & $30.33 \pm 6.91$ & $33.57 \pm 6.84$ & $27.50 \pm 5.77$ & $<0.001$ \\
\hline $\mathrm{PaO}_{2}(\mathrm{mmHg})$ & $75.40 \pm 27.72$ & $77.82 \pm 38.21$ & $73.28 \pm 14.49$ & 0.778 \\
\hline $\mathrm{PaCO}_{2}(\mathrm{mmHg})$ & $36.74 \pm 7.06$ & $37.84 \pm 6.86$ & $35.78 \pm 7.32$ & 0.435 \\
\hline $\mathrm{PaO}_{2} / \mathrm{FiO}_{2}(\mathrm{mmHg})$ & $141.34 \pm 46.18$ & $132.13 \pm 50.77$ & $149.41 \pm 41.71$ & 0.315 \\
\hline $\mathrm{SvO}_{2}(\%)$ & $70.19 \pm 7.10$ & $69.61 \pm 6.75$ & $70.70 \pm 7.57$ & 0.684 \\
\hline $\mathrm{D}(\mathrm{a}-\mathrm{v}) \mathrm{O}_{2}(\mathrm{~mL} / \mathrm{dL})$ & $3.35 \pm 0.55$ & $3.35 \pm 0.60$ & $3.36 \pm 0.53$ & 0.963 \\
\hline $\mathrm{pHa}$ & $7.35 \pm 0.04$ & $7.35 \pm 0.04$ & $7.35 \pm 0.03$ & 0.755 \\
\hline
\end{tabular}

ARDS: acute respiratory distress syndrome; $\mathrm{PH}$ : pulmonary hypertension; PEEP: positive end-expiratory pressure; RSC: respiratorysystem compliance; PP: peak pressure; $\mathrm{PaO}_{2}$ : partial pressure of arterial $\mathrm{O}_{2} ; \mathrm{PaCO}_{2}$ partial pressure of arterial $\mathrm{CO}_{2} ; \mathrm{FIO}_{2}$ : fraction of inspired $\mathrm{O}_{2} ; \mathrm{SvO}_{2}$ : mixed venous oxygen saturation; $\mathrm{D}(\mathrm{a}-\mathrm{v}) \mathrm{O}_{2}$ : arteriovenous oxygen difference; pHa: potential of hydrogen. The Student $t$-test was used for statistical analyses.

\section{Discussion}

The true prevalence of $\mathrm{PH}$ is unknown. Different groups $(10,12)$ have found a high prevalence of $\mathrm{PH}$ in patients with ARDS; however, those studies included heterogeneous patient populations with cardiopulmonary problems prior to the event that precipitated acute ARDS, or other comorbidities that are associated with the prior existence of $\mathrm{PH}$. Moreover, the selection criteria used in these previous studies were overly broad and did not all use the same definition of PH. Zapol et al. (10), in 1977, were the first to note the existence of $\mathrm{PH}$ in patients with ARDS and its influence on survival. All 30 patients in their study were said to have $\mathrm{PH}$, but the diagnostic criteria were not stated, and the cohort consisted of patients with different etiologies and disease severity, as shown by the use of partial venoarterial bypass in eight patients and the high mortality (80\%). In a study by Sibbald et al. (20), the prevalence of $\mathrm{PH}$ in patients with ARDS and sepsis was $72.5 \%$ (37/51); however, $\mathrm{PH}$ was defined as mPAP $>19 \mathrm{mmHg}$. Beiderlinden et al. (12) reported a $\mathrm{PH}$ prevalence of $92.2 \%(95 / 103)$ in a group of critically ill patients with ARDS diagnosed according to the criteria proposed by Murray et al. (21) in 1988. These patients had been referred from other hospitals as a result of treatment failure, which suggests that they were in the late stages of ARDS. However, there was no discussion of any preexisting cardiopulmonary disease that could have explained

Table 4. Hemodynamic profile of survivors and non-survivors.

\begin{tabular}{lcc}
\hline & Survivors $(\mathrm{n}=19)$ & Non-survivors $(\mathrm{n}=11)$ \\
\hline HR $(\mathrm{bpm})$ & $90.47 \pm 19.66$ & $96.54 \pm 19.03$ \\
$\mathrm{RAP}(\mathrm{mmHg})$ & $9.42 \pm 2.56$ & $9.55 \pm 2.80$ \\
SPAP $(\mathrm{mmHg})$ & $38.16 \pm 14.22$ & $36.64 \pm 13.51$ \\
dPAP $(\mathrm{mmHg})$ & $23.26 \pm 9.93$ & $20.36 \pm 6.12$ \\
$\mathrm{mPAP}(\mathrm{mmHg})$ & $28.32 \pm 10.98$ & $24.91 \pm 9.08$ \\
dPAP-POAP $(\mathrm{mmHg})$ & $12.63 \pm 9.92$ & $9.18 \pm 5.79$ \\
POAP $(\mathrm{mmHg})$ & $10.63 \pm 3.18$ & $11.18 \pm 2.71$ \\
$\mathrm{Cl}\left(\mathrm{L} \cdot \mathrm{min}^{-1} \cdot \mathrm{m}^{-2}\right)$ & $3.15 \pm 0.67$ & $3.84 \pm 1.03$ \\
RVSWI $\left(\mathrm{g} \cdot \mathrm{min}^{-1} \cdot \mathrm{m}^{-2}\right)$ & $8.41 \pm 5.38$ & $10.55 \pm 4.25$ \\
LVSWI $\left(\mathrm{g} \cdot \mathrm{min}^{-1} \cdot \mathrm{m}^{-2}\right)$ & $39.43 \pm 12.85$ & $39.61 \pm 11.72$ \\
SVRI $\left(\right.$ dynas $\left.\cdot \mathrm{s}^{-1} \cdot \mathrm{cm}^{-5} \cdot \mathrm{cm}^{-2}\right)$ & $1852 \pm 732.53$ & $1758 \pm 560.80$ \\
PVRI $\left(\right.$ dynas $\left.\cdot \mathrm{s}^{-1} \cdot \mathrm{cm}^{-5} \cdot \mathrm{cm}^{-2}\right)$ & $381.95 \pm 271.63$ & $352.82 \pm 216.22$ \\
\hline
\end{tabular}

HR: heart rate, RAP: right atrial pressure; sPAP: systolic pulmonary artery pressure; dPAP: diastolic pulmonary artery pressure; mPAP mean pulmonary artery pressure; PAOP: pulmonary artery occlusion pressure; Cl: cardiac index; RVSWI: right ventricular stroke work index; LVSWI: left ventricular stroke work index; SVRI: systemic vascular resistance index; PVRI: pulmonary vascular resistance index. There were no significant differences between the profiles of survivors and non-survivors (Student $t$-test). 
Table 5. Blood gas and ventilatory parameters and SOFA score of survivors and non-survivors.

\begin{tabular}{lccr}
\hline & Survivors $(n=19)$ & Non-survivors $(n=11)$ & \multicolumn{1}{c}{$P$} \\
\hline PEEP $\left(\mathrm{cmH}_{2} \mathrm{O}\right)$ & $12.32 \pm 3.60$ & $12.18 \pm 3.84$ & 0.924 \\
$\mathrm{PP}\left(\mathrm{cmH}_{2} \mathrm{O}\right)$ & $30.32 \pm 7.15$ & $30.36 \pm 6.80$ & 0.986 \\
$\mathrm{PaO}_{2}(\mathrm{mmHg})$ & $75.95 \pm 32.96$ & $74.44 \pm 16.47$ & 0.888 \\
$\mathrm{PaCO}_{2}(\mathrm{mmHg})$ & $34.51 \pm 5.15$ & $40.59 \pm 8.44$ & $<0.001$ \\
$\mathrm{PaO}_{2} / \mathrm{FiO}_{2}(\mathrm{mmHg})$ & $144.64 \pm 47.84$ & $135.64 \pm 44.81$ & 0.616 \\
$\mathrm{SvO}_{2}(\%)$ & $69.18 \pm 6.46$ & $71.92 \pm 8.11$ & 0.317 \\
$\mathrm{D}(\mathrm{a}-\mathrm{v}) \mathrm{O}_{2}(\mathrm{~mL} / \mathrm{dL})$ & $3.43 \pm 0.47$ & $3.23 \pm 0.68$ & 0.367 \\
$\mathrm{pHa}$ & $7.36 \pm 0.04$ & $7.34 \pm 0.03$ & 0.181 \\
SOFA score & $8.58 \pm 2.47$ & $11.18 \pm 3.15$ & $<0.001$ \\
\hline
\end{tabular}

SOFA: sequential organ failure assessment; PEEP: positive end-expiratory pressure; PP: peak pressure; $\mathrm{PaO}_{2}$ : partial pressure of arterial $\mathrm{O}_{2} ; \mathrm{PaCO}_{2}$ partial pressure of arterial $\mathrm{CO}_{2} ; \mathrm{FIO}_{2}$ : fraction of inspired $\mathrm{O}_{2} ; \mathrm{SvO}_{2}$ : mixed venous oxygen saturation; $\mathrm{D}(\mathrm{a}-\mathrm{v}) \mathrm{O}_{2}$ : arteriovenous oxygen difference; $\mathrm{pHa}$ : potential of hydrogen. The Student $t$-test was used for statistical analyses.

the high prevalence of $\mathrm{PH}$ in the study patients.

In this study, we reported our experience with 30 patients with established ARDS (6), who underwent hemodynamic monitoring using PAC upon admission to the ICU. The diagnosis of PH was made by the currently accepted hemodynamic (mPAP $>25 \mathrm{mmHg}$ ) (2-4) and echocardiographic criteria, as previously reported (22-24). When selecting the study participants, special care was taken not to include any with clinical conditions (e.g., cardiac or respiratory disease) that might have predisposed them to $\mathrm{PH}$ before the onset of ARDS. This might be reflected by the existence of a normal PAOP in our cohort. We found a $\mathrm{PH}$ prevalence of $46.6 \%$ in patients with ARDS, which differs from that found in previous studies. This difference from the earlier studies can be explained by our strict selection criteria. The analysis of the hemodynamic profile of patients with $\mathrm{PH}$ shows that even though our cohort included patients with sepsis, cardiac output was not different from those without $\mathrm{PH}$. The analysis also shows that the crucial site of PVR was at the pre-capillary level, indicated by the existence of dPAP and PAOP gradients of $>5 \mathrm{mmHg}$. Resistance at this level may be determined by active processes (e.g., hypoxemia, acidosis, or hypercapnia) or pathophysiological insults such as structural damage, vascular remodeling, thrombosis, or perivascular edema. However, resistance can also result from changes in intrathoracic pressure produced by mechanical ventilation. The lack of differences in gas exchange variables between patients with and without $\mathrm{PH}$ suggests the absence of vasoactive factors. Taken together, these results suggest that changes in intrathoracic pressure mediated by mechanical ventilation play a role in the genesis of $\mathrm{PH}$.

The effect of increased airway pressure on pulmonary hemodynamics can be explained by the relationship between PVR and lung volume. At low lung volumes, near residual volume (RV), PVR is high. This resistance decreases in the level of functional residual capacity and increases significantly again when the lung is inflated to total lung capacity (TLC). The behavior of the right ventricular pressure is explained by the participation of two types of vessels; extra-alveolar vessels that are subject to changes in pleural pressure and intra-alveolar vessels that are subject to changes in alveolar pressure. At the RV, resistance is low in the alveolar vessels but increased in the extra-alveolar vessels because the transmural pressure is low. At TLC, the pleural pressure is negative; a negative transmural pressure dilates extra-alveolar vessels and reduces their resistance. However, when alveolar pressure is positive, the transmural pressure of intra-alveolar vessels increases and their resistance decreases. The increase in PVR at RV is explained by the collapse of extraalveolar vessels, while the increase in PVR at TLC can be explained by the collapse of alveolar vessels. As ARDS evolves, significant and progressive increases in airway pressures are often required to maintain oxygenation, which can lead to alveolar over-distention. It is likely that in our population, the increases in intrathoracic pressure required to maintain adequate gas exchange were associated with the existence of $\mathrm{PH}$. The requirement of higher intrathoracic pressure in patients with $\mathrm{PH}$ suggests the presence of more severe lung damage. Our study does not establish this possibility with certainty. It is not possible, for example, to rule out the existence of thrombotic events or more severe structural vascular changes in those patients with $\mathrm{PH}$.

Some studies suggest that PH may cause acute cor pulmonale $(A C P)$ in patients with ARDS. The incidence of ACP in patients with ARDS has been reported in echocardiographic studies conducted by Jardin and colleagues (22-24). In 1985, that group reported a $61 \%$ incidence of ACP in ARDS, but it had decreased to $25 \%$ by $2001(23,25)$. To explain this decrease, the authors emphasized the implementation of the lung-protective strategy $(21,25)$ proposed by ARDSnet $(6)$. This strategy aims to limit the airway pressure and, therefore, reduce 
lung over-distention and thus transpulmonary pressure. This method is thought to reduce the compression of intraalveolar vessels during mechanical ventilation, and, therefore, acts to decrease RV afterload. In this context, the impact of ACP can be related to the level of pressure in the airway. Jardin and Vieillard-Baron (22), using an echocardiographic diagnosis of ACP in patients with ARDS, reported an incidence of $13 \%$ when the plateau pressure was maintained between 18 and $26 \mathrm{cmH}_{2} \mathrm{O}, 32 \%$ if the plateau pressure was between 27 and $35 \mathrm{cmH}_{2} \mathrm{O}$, and $56 \%$ when plateau pressure exceeded $35 \mathrm{cmH}_{2} \mathrm{O}$. Osman et al. (19) reported the incidence of RVF in 145 patients with ARDS ventilated using the lung-protective strategy. Using the hemodynamic criteria defined by the association of RVF with $\mathrm{mPAP}>25 \mathrm{mmHg}$, central venous pressure $>\mathrm{PAOP}$, and stroke volume index $<30 \mathrm{~L} / \mathrm{min}$, they reported an RVF incidence of $9.6 \%$, which can be explained by the use of the lung-protective strategy, and by a definition of RVF that included a low stroke volume index. Using the hemodynamic definition proposed by Osman et al. (19), we found that only one patient developed RVF, which can also be explained by the implementation of a lung protection strategy.

The influence of $\mathrm{PH}$ on the prognosis of patients with ARDS is not certain. Different studies have shown that $\mathrm{PH}$ may be a risk factor for increased mortality in patients with ARDS. Squara et al. (13) studied 586 patients with ARDS, reporting that the group of patients who died had a higher mPAP. In contrast, Page et al. (26) reported an APC incidence of $25 \%$ in 75 patients with ARDS and found no difference in mortality when comparing the group with and without APC. Similarly, Osman et al. (19) reported that the presence of RVF in patients with ARDS did not influence prognosis. Our study reports similar data to those presented by Squara et al. (13) and Osman et al. (19).

\section{References}

1. Simonneau G, Galie N, Rubin LJ, Langleben D, Seeger W, Domenighetti $\mathrm{G}$, et al. Clinical classification of pulmonary hypertension. J Am Coll Cardiol 2004; 43: 5S-12S, doi: 10.1016/j.jacc.2004.02.037.

2. McLaughlin VV, Archer SL, Badesch DB, Barst RJ, Farber HW, Lindner JR, et al. ACCF/AHA 2009 expert consensus document on pulmonary hypertension a report of the American College of Cardiology Foundation Task Force on Expert Consensus Documents and the American Heart Association developed in collaboration with the American College of Chest Physicians; American Thoracic Society, Inc.; and the Pulmonary Hypertension Association. J Am Coll Cardiol 2009; 53: 1573-1619, doi: 10.1016/j.jacc.2009.01.004.

3. Hoeper MM, Bogaard HJ, Condliffe R, Frantz R, Khanna D, Kurzyna M, et al. Definitions and diagnosis of pulmonary hypertension. J Am Coll Cardiol. 2013; 62 (Suppl 25): D42D50, doi: 10.1016/j.jacc.2013.10.032.

4. Rubin LJ. Primary pulmonary hypertension. N Engl J Med 1997; 336: 111-117, doi: 10.1056/NEJM199701093360207.
The degree of pulmonary hypertension did not influence mortality $(37.5 \%$ in the group without $\mathrm{PH}$ versus $35.7 \%$ in the group with $\mathrm{PH}$ ). In our cohort, mortality correlated with the extent of organ failure as established by the SOFA score at ICU admission, reflecting the findings of previous studies $(14,20)$. Interestingly, $\mathrm{PaCO}_{2}$ levels in ICU survivors and those who died were different, which suggests that more severe lung injury is a risk for death.

\section{Study limitations}

Our study has some limitations in that it represents the experience of a single center and the sample size was small. However, we believe that the prevalence of $\mathrm{PH}$ associated with ARDS reported in this study, using stricter selection criteria and updated diagnostic criteria, is in line with the current realities of clinical management.

\section{Conclusion}

The prevalence of $\mathrm{PH}$ in patients with ARDS was $46.6 \%$. The degree of $\mathrm{PH}$ was considered mild to moderate, and the presence of $\mathrm{PH}$ did not correlate with RVF. We have established for the first time, in our ARDS patients, that the level of airway pressure seems to be associated with the existence of $\mathrm{PH}$, and the extent of $\mathrm{PH}$ does not seem to influence survival. Rather, survival is determined by the severity of organ failure on admission to the ICU.

\section{Acknowledgments}

We would like to thank the nurses and medical staff in the ICU at the Instituto Nacional de Ciencias Médicas y Nutrición Salvador Zubirán, Mexico City, Mexico for their assistance in the care of these patients.
5. Atabai $\mathrm{K}$, Matthay MA. The pulmonary physician in critical care. 5: Acute lung injury and the acute respiratory distress syndrome: definitions and epidemiology. Thorax 2002; 57 : 452-458, doi: 10.1136/thorax.57.5.452.

6. Ranieri VM, Rubenfeld GD, Thompson BT, Ferguson ND, Caldwell E, Fan E, et al. Acute respiratory distress syndrome: the Berlin Definition. JAMA 2012; 307: 2526-2533.

7. Frutos-Vivar F, Nin N, Esteban A. Epidemiology of acute lung injury and acute respiratory distress syndrome. Curr Opin Crit Care 2004; 10: 1-6, doi: 10.1097/00075198-20040200000001.

8. Bernard GR. Acute respiratory distress syndrome: a historical perspective. Am J Respir Crit Care Med 2005; 172: 798-806, doi: 10.1164/rccm.200504-663OE.

9. Esteban A, Anzueto A, Frutos F, Alia I, Brochard L, Stewart $\mathrm{TE}$, et al. Characteristics and outcomes in adult patients receiving mechanical ventilation: a 28-day international study. JAMA 2002; 287: 345-355, doi: 10.1001/jama.287.3.345.

10. Zapol WM, Snider MT. Pulmonary hypertension in severe 
acute respiratory failure. N Engl J Med 1977; 296: 476-480, doi: 10.1056/NEJM197703032960903.

11. McLaughlin VV, Rich S. Severe pulmonary hypertension: critical care clinics. Crit Care Clin 2001; 17: 453-467, doi: 10.1016/S0749-0704(05)70177-9

12. Beiderlinden M, Kuehl H, Boes T, Peters J. Prevalence of pulmonary hypertension associated with severe acute respiratory distress syndrome: predictive value of computed tomography. Intensive Care Med 2006; 32: 852-857, doi: 10.1007/s00134-006-0122-9.

13. Squara $P$, Dhainaut JF, Artigas A, Carlet J. Hemodynamic profile in severe ARDS: results of the European Collaborative ARDS Study. Intensive Care Med 1998; 24: 1018-1028, doi: 10.1007/s001340050710.

14. Knaus WA, Draper EA, Wagner DP, Zimmerman JE. APACHE II: a severity of disease classification system. Crit Care Med 1985; 13: 818-829, doi: 10.1097/00003246198510000-00009.

15. Vincent JL, de Mendonça A, Cantraine F, Moreno R, Takala $\mathrm{J}$, Suter PM, et al. Use of the SOFA score to assess the incidence of organ dysfunction/failure in intensive care units: results of a multicenter, prospective study. Working group on "sepsis-related problems" of the European Society of Intensive Care Medicine. Crit Care Med 1998; 26: 17931800, doi: 10.1097/00003246-199811000-00016.

16. Summerhill EM, Baram M. Principles of pulmonary artery catheterization in the critically ill. Lung 2005; 183: 209-219, doi: 10.1007/s00408-004-2537-9.

17. The Acute Respiratory Distress Syndrome Network. Ventilation with lower tidal volumes as compared with traditional tidal volumes for acute lung injury and the acute respiratory distress syndrome. N Engl J Med 2000; 342: 13011308, doi: 10.1056/NEJM200005043421801.

18. Brower RG, Lanken PN, Maclntyre N, Matthay MA, Morris A, Ancukiewicz M, et al. Higher versus lower positive endexpiratory pressures in patients with the acute respiratory distress syndrome. N Engl J Med 2004; 351: 327-336, doi:
10.1056/NEJMoa032193

19. Osman D, Monnet X, Castelain V, Anguel N, Warszawski J, Teboul JL, et al. Incidence and prognostic value of right ventricular failure in acute respiratory distress syndrome. Intensive Care Med 2009; 35: 69-76, doi: 10.1007/s00134008-1307-1.

20. Sibbald WJ, Paterson NA, Holliday RL, Anderson RA, Lobb TR, Duff JH. Pulmonary hypertension in sepsis: measurement by the pulmonary arterial diastolic-pulmonary wedge pressure gradient and the influence of passive and active factors. Chest 1978; 73: 583-591, doi: 10.1378/chest.73.5.583.

21. Murray JF, Matthay MA, Luce JM, Flick MR. An expanded definition of the adult respiratory distress syndrome. Am Rev Respir Dis 1988; 138: 720-723, doi: 10.1164/ajrccm/138.3. 720.

22. Jardin F, Vieillard-Baron A. Is there a safe plateau pressure in ARDS? The right heart only knows. Intensive Care Med 2007; 33: 444-447, doi: 10.1007/s00134-007-0552-z.

23. Vieillard-Baron A, Schmitt JM, Augarde R, Fellahi JL, Prin S, Page $B$, et al. Acute cor pulmonale in acute respiratory distress syndrome submitted to protective ventilation: incidence, clinical implications, and prognosis. Crit Care Med 2001; 29 : 1551-1555, doi: 10.1097/00003246-200108000-00009.

24. Jardin F, Fellahi JL, Beauchet A, Vieillard-Baron A, Loubieres $\mathrm{Y}$, Page $\mathrm{B}$. Improved prognosis of acute respiratory distress syndrome 15 years on. Intensive Care Med 1999; 25: 936941, doi: 10.1007/s001340050985.

25. Jardin F, Gueret P, Dubourg O, Farcot JC, Margairaz A, Bourdarias JP. Two-dimensional echocardiographic evaluation of right ventricular size and contractility in acute respiratory failure. Crit Care Med 1985; 13: 952-956, doi: 10.1097/00003246-198511000-00035.

26. Page B, Vieillard-Baron A, Beauchet A, Aegerter P, Prin S, Jardin F. Low stretch ventilation strategy in acute respiratory distress syndrome: eight years of clinical experience in a single center. Crit Care Med 2003; 31: 765-769, doi: 10.1097/ 01.CCM.0000055402.68581.DC. 